\title{
Gains from cataract surgery: visual function and quality of life
}

\author{
P Desai, A Reidy, D C Minassian, G Vafidis, J Bolger
}

Royal College of Ophthalmologists, London NW1 4QW P Desai

Public Health Directorate, Barnet Health Agency, Colindale Hospital, London NW9 5HG A Reidy

\section{Department of Preventive Ophthalmology, Institute of Ophthalmology, London EC1V 9EL P Desai \\ D C Minassian}

The Wellhouse Trust, Edgware, Middlesex HA8 0AD $G$ Vafidis

Queen Elizabeth II Hospital, Welwyn Garden City, Herts AL7 4HQ J Bolger

Correspondence to: Ms Parul Desai, Southampton Eye Unit, Southampton General Hospital, Tremona Road, Southampton SO16 6YD

\begin{abstract}
Aims-To describe the impact of cataract surgery in terms of visual function (functioning in everyday life with respect to vision dependent activities) and health related quality of life.

Methods-An observational, longitudinal study of patients undergoing cataract surgery was carried out at three district general hospitals in outer London districts of North Thames Region with follow up at 4 and 12 months postoperatively for a clinical assessment and a standardised administered interview. Patients were admitted for surgery to the first eye for age-related cataract between 1 May 1993 and 31 August 1994. Visual functioning was assessed by the VF-14, health related quality of life was assessed by the sickness impact profile (SIP), and vision related quality of life was assessed by VR-SIP (a modification of the generic SIP).

Results-Significant gains in all the outcome measures were demonstrated at 4 months postoperatively. No significant change (gain or loss) was observed between 4 and 12 months after surgery to the first eye. Postoperatively, the mean visual function (VF-14) scores, and health related (SIP) and vision related (VR-SIP) quality of life scores, indicated less reported trouble with vision dependent activities and better perceived quality of life, respectively. The average gains in visual function and quality of life (health and vision related) were apparent in groups with good visual outcome and poor visual outcome. Significant additional gains were seen at 1 year in patients who had second eye surgery in the interval between the postoperative assessments.

Conclusions-Gains in visual functioning and quality of life (health and vision related) have been demonstrated following cataract surgery. These gains were sustained at 1 year after surgery to the first eye, with additional gains being conferred if second eye surgery had been performed. Assessment of the outcomes of cataract surgery by clinical indicators alone may underestimate the overall benefits of surgery, particularly in patients with poor visual outcome.

(Br F Ophthalmol 1996;80:868-873)
\end{abstract}

The aim of cataract surgery is to improve visual acuity and thereby improve visual function, with the implicit assumption that this will also improve overall quality of life. The gains from cataract extraction are usually demonstrated clinically, by the change in Snellen visual acuity in the eye that had surgery. The impact on visual function (that is, functioning in everyday life with respect to vision dependent activities), or quality of life has not usually been considered as a separate issue, partly as these have been assumed to follow the improvement in visual acuity, and also because the methods and instruments required to make these types of assessments have not been readily available for use in patients with visual disorders. The length of time taken to complete these types of measures, and their mode of administration combined with the lack of familiarity (particularly among clinicians) with the scores produced and their interpretation, are some of the factors that have inhibited their use in routine practice. With the current trend in outcomes assessment placing equal importance on patient perceived outcomes, these are now being included in the evaluation of outcomes of surgical interventions. While clinical measures can provide an objective assessment of health outcomes as a result of an intervention, patient perceived measures provide a subjective assessment of health outcomes. These latter are based on the patients' interpretation of the impact of the intervention on their daily life and circumstances.

This combined approach has been adopted in a series of studies evaluating the outcomes of cataract extraction within the National Health Service. The first of these, the National Cataract Surgery Survey, has quantified the clinical outcomes (Snellen visual acuity and surgically related complications), achieved nationally, from current surgical practice. ${ }^{1}$ Its findings clearly demonstrate the clinical gains obtained in terms of visual acuity. Eighty per cent of patients had good visual outcome (Snellen visual acuity of $6 / 6$ to $6 / 12$ ), at 3 months postoperatively, in the eye that had surgery, irrespective of preoperative visual acuity in that eye. Ocular comorbidity (other than cataract), was identified as a risk factor for poor visual outcome (less than 6/12 at 3 months postoperatively), with increasing severity of ocular comorbidity being associated with increased risk of poor visual outcome. ${ }^{1}$

Following on from this, we conducted the Cataract Outcome Study to evaluate the impact of cataract and cataract surgery on visual acuity, visual function, and health related quality of life, and the relations between these different outcomes, so that appropriate meth- 
ods and indicators for assessing the outcomes of cataract surgery could be identified. We have used instruments for the assessment of visual function and health related quality of life for the first time in the UK on cataract patients, in collaboration with the Johns Hopkins University, Baltimore, USA. This allowed for the collection of comparable data on visual function and health related quality of life for cataract patients that may be used for making international comparisons of the outcomes of cataract surgery.

This paper reports from the Cataract Outcome Study, on the overall gains from cataract surgery in terms of visual function and health related quality of life both in the short term (at 4 months) and at 1 year postoperatively.

\section{Method}

This longitudinal, observational study was located within North Thames Region, in three district general hospitals, and conducted after ethical approval had been granted from the local district ethics committees. Patients admitted for surgery for age-related cataract, for the first eye, and (subsequently for the second eye during the study period) were invited to participate in the study. Both standard extracapsular cataract extraction and phacoemulsification were performed in the participating hospitals and aphakic correction was achieved by posterior chamber intraocular lenses. The recruitment period was from 1 May 1993 to 31 August 1994 and written, informed consent was obtained before patients were recruited. Patients having combined procedures (for example, cataract surgery and filtration surgery), or surgery for other types of cataract (for example, congenital, traumatic) were excluded. Patients were followed up at 4 months and 12 months after surgery.

All data were collected on standardised proforma. Clinical data (on the process of care provided and related clinical outcomes) were collected by the ophthalmologists concurrently with routine preoperative assessments and at dedicated postoperative follow up clinics at 4 and 12 months. Data pertaining to visual function and quality of life were obtained from a standardised administered interview preoperatively, at 4 months, and 12 months after surgery. Interviews were conducted in the patients' homes by experienced trained interviewers.

The sample obtained was compared with the national sample from the National Cataract Surgery Survey ${ }^{2}$ to assess whether any effects from selection bias had been introduced.

\section{VISUAL FUNCTION}

This was assessed using the VF-14, a new instrument designed to provide a specific measure of visual functioning in cataract patients. It was developed by the Cataract PORT team and contains 14 items that include a broad spectrum of vision dependent activities performed in everyday life that may be affected by cataract. ${ }^{3}$ Patients were asked whether, even with their most recent glasses, they had any difficulty in performing the task. The responses allowed were 'yes', 'no', or 'do not do that activity for reasons unrelated to vision'. For each activity for which patients responded to as 'yes', they were asked how much difficulty they currently had with that activity-'a little', 'a moderate amount', 'a great deal', or 'unable to do' because of their vision. The score was based on all applicable items and the amount of reported difficulty experienced in performing those activities. An item was not included in the scoring if patients did not do that activity for a reason other than their vision-for example, if patients had never cooked for themselves. No minimum number of applicable items was required. The final score produced by this index ranges from 0 (unable to do all applicable activities because of vision) and a maximum of 100 (able to do all applicable items without difficulty). ${ }^{3}$

HEALTH RELATED QUALITY OF LIFE

This was assessed using the sickness impact profile (SIP). This is a well established, standardised, generic measure of perceived health related quality of life. ${ }^{4}$ It has been extensively tested for reliability and validity, ${ }^{5-8}$ and widely used among different patient groups. ${ }^{410-15}$ The SIP measures sickness related dysfunction in 12 categories : work, recreation and pastimes, emotional behaviour, alertness behaviour, home management, sleep and rest, eating, body care and management, ambulation, mobility, communication, and social interaction. Only those items which apply to respondents on the day of completion and are related to their health are endorsed. Scores are calculated using predetermined weights based on estimates of the relative severity of the dysfunction associated with the items. ${ }^{46}$ The total SIP scores range from 0 to 100 . The lower the score (towards zero), the better the respondents' health related quality of life.

\section{VISION RELATED SIP}

The vision related SIP (VR-SIP) represents a modification of the SIP for patients with problems with their vision, developed by the Cataract PORT team. Its purpose was to quantify how much of their general dysfunction patients attributed to their vision, providing a measure of vision related quality of life. Each time patients responded positively to an item contained in the SIP, they were asked whether they thought the statement applied because of their vision. Responses to the latter questions were used to calculate a total vision related SIP score in the same manner as for SIP.

\section{STATISTICAL METHODS}

As the VF-14 was a new instrument and not previously used in the UK, an assessment of its reliability and validity was performed. Reliability, in terms of the internal consistency, and criterion validity of the VF-14 are reported here. Internal consistency was assessed by cal- 
Table 1 Sample characteristics

\begin{tabular}{lll}
\hline & $\begin{array}{c}\text { Participants } \\
(n=337) \%\end{array}$ & $\begin{array}{l}\text { National sample } \\
(n=1495) \%\end{array}$ \\
\hline $\begin{array}{l}\text { Age (years) on admission: } \\
\text { 50-64 }\end{array}$ & 11.3 & 13.3 \\
$65-74$ & 29.4 & 30 \\
$\geq 75$ & 59.3 & 56.7 \\
Sex: & $+\chi^{2}=1.20 ; \mathrm{df}=2 ; \mathrm{p}=0.55$ & \\
$\quad$ Males & 38.9 & 38.5 \\
Females & 61.1 & 61.5 \\
& $+\chi^{2}=0.017 ; \mathrm{df}=1 ; \mathrm{p}=0.9$ & \\
\hline
\end{tabular}

* Sample from the National Cataract Surgery Survey. ${ }^{2}$

† Comparison between participants (study sample) and the national sample.

Table 2 Sickness impact profile (SIP) : responders and non-responders

\begin{tabular}{lll}
\hline & $\begin{array}{l}\text { SIP respondents } \\
(n=273) \%\end{array}$ & $\begin{array}{l}\text { SIP non-respondents } \\
(n=64) \%\end{array}$ \\
\hline Marital status: & & \\
$\quad$ Married & 50.2 & 54 \\
Not married & 49.8 & 46 \\
Living alone & $\chi^{2}=0.29 ; \mathrm{df}=1 ; \mathrm{p}=0.59$ & \\
Not living alone & 42.2 & 44.1 \\
& 57.8 & 55.9 \\
Type of admission: & $\chi^{2}=0.07 ; \mathrm{df}=1 ; \mathrm{p}=0.79$ & \\
Inpatient & & 65.5 \\
Day case & 53.1 & 34.5 \\
& 46.9 & \\
Preoperative visual acuity in surgery eye: & $\chi^{2}=2.77 ; \mathrm{df}=1 ; \mathrm{p}=0.09$ & 18.9 \\
6/6 to $6 / 12$ & 23.6 & 54 \\
6/18 to $6 / 24$ & 44.8 & 18.8 \\
6/36 to $6 / 60$ & 16.8 & 11.3 \\
Less than $6 / 60$ & 14.8 & \\
& $\chi^{2}=1.27 ; \mathrm{df}=3 ; \mathrm{p}=0.74$ & \\
\hline
\end{tabular}

culating Cronbach's alpha coefficient. ${ }^{16}$ Criterion validity of the VF-14 was assessed by examining the Pearson and Spearman correlation coefficient between the preoperative $\mathrm{VF}-14$ score and preoperative measures of visual acuity and quality of life. The VF-14 was expected to have better correlations with visual acuity and vision related quality of life (VR-SIP).

The significance of the change in scores postoperatively was assessed by performing both paired $t$ tests and equivalent nonparametric tests (Wilcoxon matched pair signed rank test and the sign test).

\section{Results}

A total of 337 patients were recruited into the study. Follow up data were available for 316 (93.8\%) patients at 4 months and $278(83 \%)$ patients at 12 months; 273 patients completed SIP preoperatively, with follow up data on 213
(78\%) patients at both 4 and 12 months; 86 patients had surgery to the fellow eye between 4 and 12 months after surgery to the first eye.

\section{SAMPLE CHARACTERISTICS}

The study sample was not found to be atypical of cataract patients in terms of age and sex on admission when compared with the national sample from the National Cataract Surgery Survey $^{2}$ (Table 1).

Eighty one per cent of patients completed SIP on recruitment. No important differences were identified between these patients and those who did not complete SIP, in terms of visual acuity, age, sex, marital status, whether living alone or not, and type of admission (Table 2).

\section{RELIABILITY AND VALIDITY OF THE VF-14}

The internal consistency of the VF-14 given by Cronbach's alpha was 0.74 . Criterion validity of the VF-14 given by its correlations (Spearman) with measures of vision and quality of life were in the directions expected. (Spearman correlation coefficients are presented because the distribution of the preoperative VF-14 score was highly skewed.) Significant correlations with visual acuity were demonstrated with the VF-14 having better correlation with visual acuity in the better eye $(r=0.48)$, than with visual acuity in the surgery eye $(r=0.21)$. Similarly, significant correlations were demonstrated with measures of quality of life, but with better correlations with vision related SIP $(r=0.7)$ than with the generic SIP $(r=0.37)$.

\section{POSTOPERATIVE GAINS IN VISUAL FUNCTION AND} QUALITY OF LIFE

Overall, significant gains in visual function and quality of life were observed postoperatively in both the short term ( 4 months) and long term (12 months), compared with baseline preoperative values. The impact of surgery across all measures was evident at 4 months, with no significant difference in mean scores being demonstrated between 4 and 12 months. The higher mean visual function scores postoperatively indicated less reported difficulty with vision dependent activities. The lower mean health related quality of life (SIP) and vision related quality of life (VR-SIP) scores after surgery indicated less perceived dysfunction. (Table 3).

Table 3 Visual function and quality of life scores: before and after cataract surgery

\begin{tabular}{|c|c|c|c|}
\hline & \multirow[b]{2}{*}{ Preoperative scores } & \multicolumn{2}{|l|}{ Postperative scores * } \\
\hline & & 4 Months after surgery & 12 Months after surgery \\
\hline & Mean $(95 \%$ CI) & Mean $(95 \% \mathrm{CI})$ & Mean $(95 \%$ CI) \\
\hline \multicolumn{4}{|l|}{ Visual function: } \\
\hline $\begin{array}{l}\text { VF-14 }(n=316) \\
\text { Quality of life: }\end{array}$ & $68.7(66.2$ to 71.1$)$ & 88.5 (86.6 to 90.4$)$ & $91.1(89.4$ to 92.8$)$ \\
\hline Sickness impact profile (SIP) $(n=213)$ & $12(10.8$ to 13.3$)$ & \multicolumn{2}{|c|}{ Quality of life: } \\
\hline Vision related SIP (VR-SIP) $(n=213)$ & $1.6(1.2$ to 2$)$ & $0.3(0.23$ to 0.43$)$ & $\begin{array}{l}8.1(7.1 \text { to } 9.1) \\
0.2(0.12 \text { to } 0.26)\end{array}$ \\
\hline
\end{tabular}

^ All postoperative scores are significantly different from preoperative values (paired $t$ test and equivalent non-parametric tests gave p values $<0.001$. 


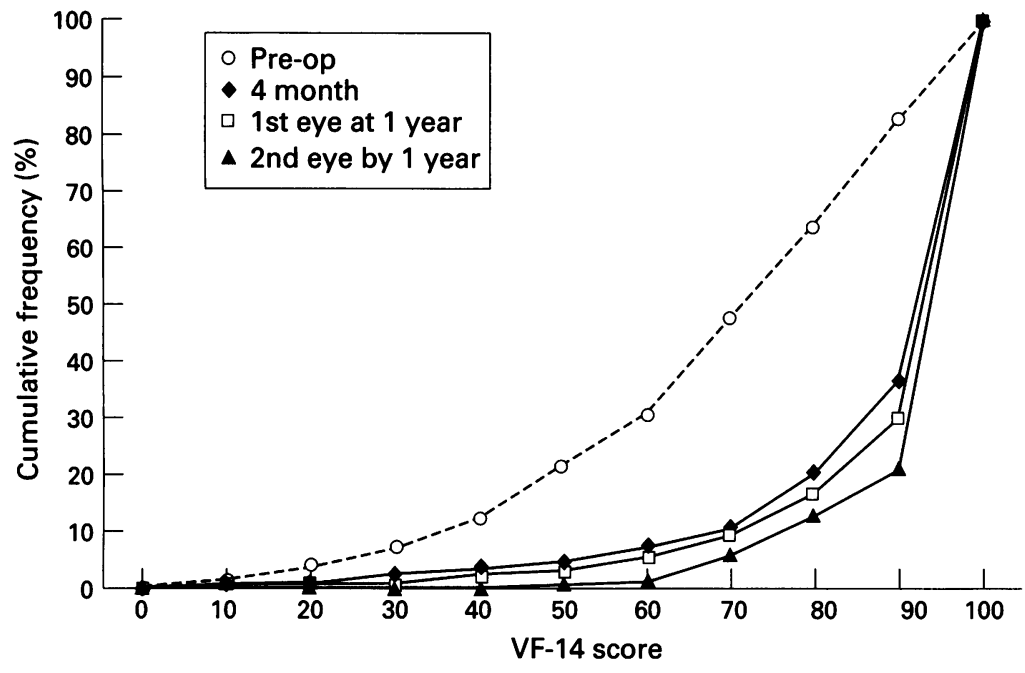

Figure 1 Visual function. VF-14 scores pre- and postoperatively.

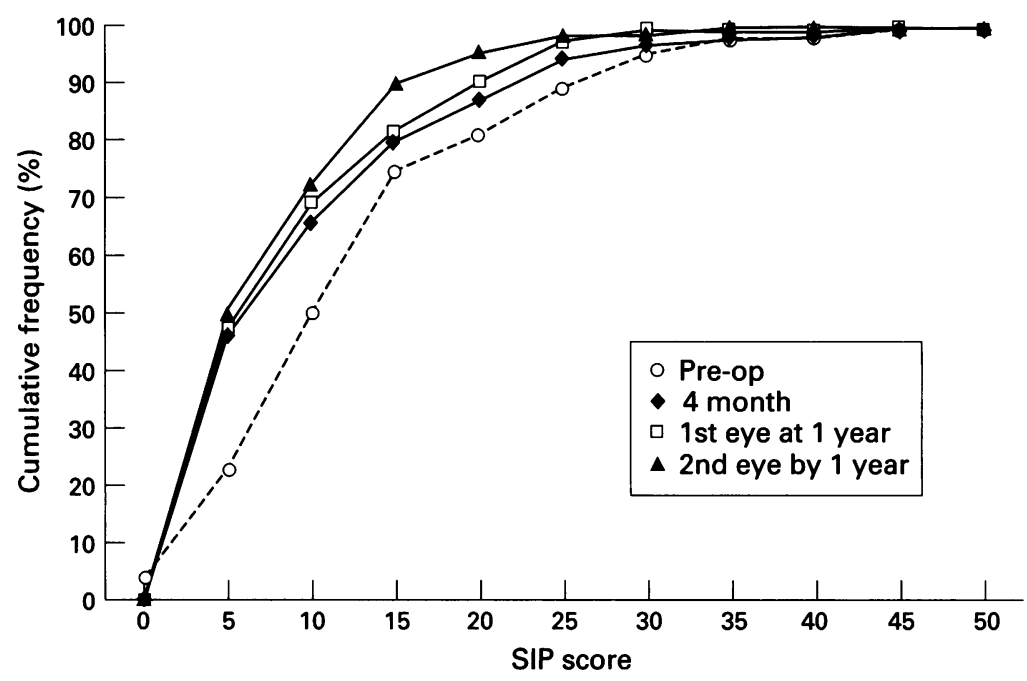

Figure 2 Health related quality of life. Sickness impact profile (SIP) scores pre- and postoperatively.

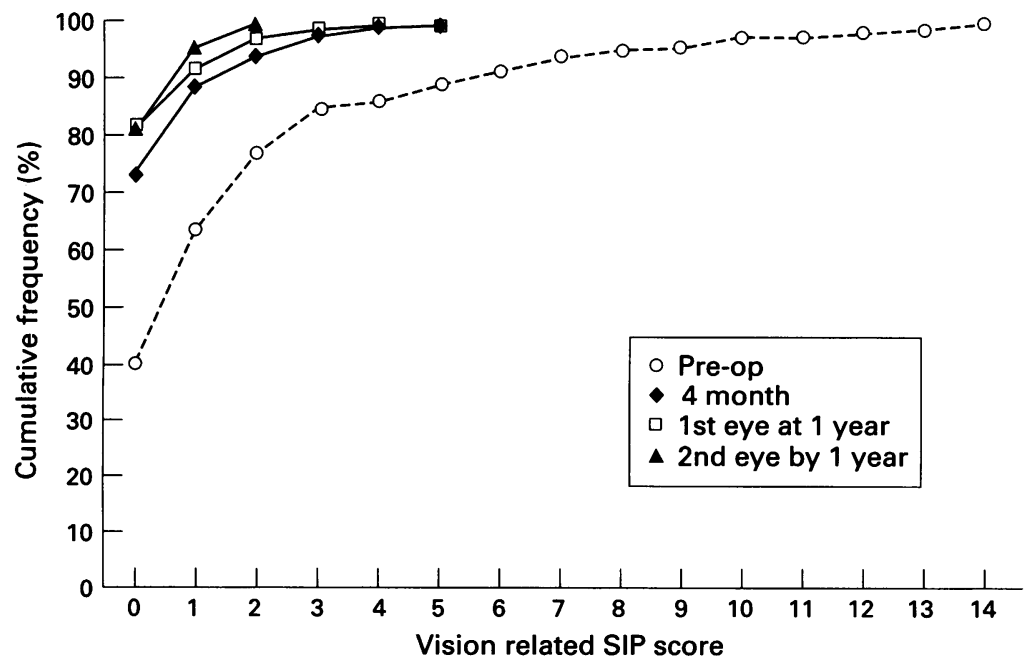

Figure 3 Vision related quality of life. Vision related sickness impact profile (VR-SIP) scores pre- and postoperatively.
Table 4 Gains from cataract surgery by visual outcome

\begin{tabular}{llll}
\hline & \multicolumn{2}{l}{$\begin{array}{l}\text { Mean gain by } 4 \text { months after surgery } \\
(S D)^{*}\end{array}$} \\
\cline { 2 - 4 } Visual outcome & $\begin{array}{c}\text { Visual } \\
\text { function }\end{array}$ & Quality of life & \multicolumn{2}{l}{ VF-14 } & SIP & VR-SIP \\
\hline Good (6/6 to 6/12) & $20.6(21.1)$ & $2.8(5.1)$ & $1.2(2.4)$ \\
Poor (less than 6/12) & $16.1(20.2)$ & $5.8(5.8)$ & $2.9(3.8)$ \\
All & $19.9(20.9)$ & $3.2(5.2)$ & $1.4(2.7)$ \\
\hline
\end{tabular}

* All were significant gains compared with baseline values: p value $<0.001$.

No significant differences in mean change were demonstrated between visual outcome groups: $p>0.05$.

\section{Short term gains}

The overall shift of the distributions of scores after cataract surgery towards scores of less dysfunction for either visual function, health, or vision related quality of life was most apparent at 4 months (Figs 1-3). Before surgery $36 \%$ of patients had a visual function score of 80 or greater, while $81 \%$ achieved this score at 4 months after surgery. Preoperatively, $22.5 \%$ of patients had SIP scores of less than 5 (associated with general populations of primarily well adults ${ }^{17}$ ), with $46 \%$ achieving this score at 4 months; and $40 \%$ of patients had VR-SIP scores of 0 preoperatively (indicating no dysfunction), with $73 \%$ having this score at 4 months.

Eight five per cent of patients achieved a good visual outcome at 4 months (Snellen acuity of $6 / 12$ or better in the surgery eye). Significant mean gains in visual function and health and vision related quality of life were achieved in subgroups of patients with good visual outcome and poor visual outcome compared with baseline preoperative values (Table 4).

\section{Long term gains}

Although no significant overall gains were demonstrated between 4 and 12 months after surgery, many patients had second eye surgery within this interval. No significant gain in visual function or health related quality of life was observed between 4 and 12 months in those patients that had only first eye surgery. However, patients who had second eye surgery had significant gains across all measures in the interval between 4 and 12 months (Table 5), resulting in a further shift of the distribution of scores at 12 months towards improved status (Figs 1-3).

\section{Discussion}

No important selection biases were observed to have been operating in the recruitment of this study sample, which may be regarded as a representative sample of cataract patients. The VF-14 displayed acceptable reliability and validity. ${ }^{3}$

Cataract extraction is a clinically effective, and safe, surgical procedure and sight threatening complications are rare. ${ }^{118}$ The findings from this study quantify the gains (short term and at 1 year) following cataract surgery in three further areas: visual function, health related, and vision related quality of life. The 
Table 5 Long term gains at 12 months after cataract surgery

\begin{tabular}{|c|c|c|c|c|}
\hline & \multicolumn{2}{|c|}{ First eyes only by 12 months } & \multicolumn{2}{|c|}{ Both eyes by 12 months } \\
\hline & $\begin{array}{l}4 \text { Month score } \\
\text { Mean (SD) }\end{array}$ & $\begin{array}{l}12 \text { Month score } \\
\text { Mean (SD) }\end{array}$ & $\begin{array}{l}4 \text { Month score } \\
\text { Mean (SD) }\end{array}$ & $\begin{array}{l}12 \text { Month score } \\
\text { Mean (SD) }\end{array}$ \\
\hline \multicolumn{5}{|l|}{ Visual function ${ }^{\star}$ : } \\
\hline VF-14 & $89.3(17)$ & $90.1(15.9)$ & $88.3(16)$ & $93.4(10.2) \ddagger$ \\
\hline \multicolumn{5}{|l|}{ Quality of life ${ }^{\star \star}$ : } \\
\hline Sickness impact profile (SIP) & $8(7.9)$ & $8.5(8.2)$ & $9.1(8.3)$ & $7.3(6.8) \ddagger$ \\
\hline Vision related SIP & $0.33(0.79)$ & $0.22(0.58) \dagger$ & $0.26(0.55)$ & $0.13(0.33) \ddagger$ \\
\hline
\end{tabular}

$\star$ VF-14: first eyes $n=192$; second eyes $n=86$.

$\star \star$ SIP and VR-SIP: first eyes $n=145$; second eyes $n=72$

† Significant gain between 4 and 12 months when first eye surgery only; paired $t$ test, $\mathrm{p}=0.02$.

$\ddagger$ Significant gain between 4 and 12 months, when second eye surgery performed during this interval; paired $t$ test, $p<0.05$.

findings indicate that the greatest impact of surgery on visual function and quality of life (health and vision related) is apparent by 4 months, with the mean gains achieved by this time being sustained at 1 year following surgery to the first eye. Recent reports (from the USA), ${ }^{3}{ }^{19}{ }^{20}$ relevant to current surgical practice for cataract, have focused primarily on visual function while the effect of surgery on patients' quality of life has received less evaluative attention. While it may be possible to demonstrate gains from cataract surgery quite early in the postoperative period, it was considered that by 4 months after surgery it was more likely that visual recovery and rehabilitation would have stabilised, irrespective of the type of procedure performed or the postoperative management provided, thereby allowing for a more appropriate assessment of the gains that patients were likely to achieve.

It is estimated that at least 105000 cataract operations are performed annually within the National Health Service, with at least a third of these being second eye procedures. ${ }^{2}$ The data on second eye surgery in this study were from patients who had surgery to the first eye, with subsequent surgery to the second eye. As such, the findings indicate that significant additional gains in visual function and quality of life (health related and vision related), were achieved after second eye surgery. These, together with the other benefits of second eye surgery that have been reported, ${ }^{19}{ }^{21}$ suggest that the value of second eye surgery should not be overlooked in the management of cataract.

The main aims of cataract surgery are achieved in the vast majority of patients. The findings also indicate that mean gains in visual function and health and vision related quality of life may be achieved in the subgroup of patients with poor visual outcome. The outcomes of cataract extraction assessed on just clinical measures may underestimate the overall benefits of surgery, particularly in the subgroup of patients who do not have a good visual outcome.

Whether these (or similar) measures should be used routinely for the assessment of cataract outcomes, requires further consideration of the meaning and interpretation of the scores provided by these instruments, in light of their relations with clinical and demographic factors. These are the subject of a series of subsequent reports.

\section{Key points}

1 Gains in visual function and health and vision related quality of life are observed in most patients after cataract surgery.

2 The mean gains in visual function, health, and vision related quality of life are apparent by 4 months after surgery.

3 The mean gains in visual function, health, and vision related quality of life are maintained at 1 year after surgery to the first eye.

4 Second eye surgery confers additional gain in visual function, health, and vision related quality of life.

We thank all the patients who gave their invaluable support and contribution throughout this study; Mr Don Fraser and Mrs Ros Wastell, project workers for the Cataract Outcome Study; Mrs C Nimalasena, Mr T Fallon, Mr J Joseph, Mr T Coker, Mr K Kleanthous, all the staff of the and the departments and the clerical and administrative staff of the participating centres; Mr J McGill, Miss Marisa Tomlinson, Miss Kelly Smith of the Royal College of Ophthalmologists; Dr S Farrow, director of public health, Barnet Health Agency; Dr B Tennison, director of public health, Hertfordshire Health Authority; Dr EP Steinberg, principal investigator, Cataract PORT, in collaborating with the use of the VF-14, SIP, and VR-SIP.

PD was supported by Core Audit Funding from the Department of Health at the Royal College of Ophthalmologists, London.

The Cataract Outcome Study was supported by a grant from the Department of Health.

1 Desai P. The National Cataract Surgery Survey: II. Clinical outcomes. Eye 1993;7:489-94.

2 Courtney P. The National Cataract Surgery Survey: I. Methods and descriptive features. Eye 1992;6:487-92.

3 Steinberg EP, Tielsch JM, Schein OD, Javitt JC, Sharkey P Cassard SD, et al. The VF-14. An index of visual functional impairment in patients with cataract. Arch Ophthalmol 1994;112:630-8

4 Bergner M, Bobbitt RA, Carter WB, Gilson BS. The Sickness Impact Profile: development and final revision of a health status measure. Med Care 1981;19:787-805.

5 Pollard WE, Bobbitt RA, Bergner M, Martin DP, Gilson BS. The Sickness Impact Profile: reliability of a health status measure. Med Care 1976;14:146-55.

6 Gilson BS, Gilson JS, Bergner M, Bobbitt R, Kressel S, Pollard W, et al. The Sickness Impact Profile: Development of an outcome measure of health care. Am $\not{f}$ Public Health 1975;65:1304-10

7 Carter WB, Bobbitt RA, Bergner M, Gilson BS. Validation of an interval scaling: the Sickness Impact Profile. Health Serv Res 1976;11:516-28

8 Bergner M, Bobbitt RA, Pollard WE, Martin DP, Gilson BS. The Sickness Impact Profile: validation of health BS. The Sickness Impact Profile: valid
status measure. Med Care 1976;14:56-67.

9 Bergner LH, Hallstrom AP, Bergner M, Eisenberg MS, Cobb LA. Health status of survivors of cardiac arrest and myocardial infarction controls. Am $\mathcal{f}$ Public Health 1985;75:1321-3. 
10 Deyo RA, Inui TS, Leininger JD, Overman S. Physical and psychosocial function in rheumatoid arthritis. Arch Intern Med 1982;142:879-82.

11 Hart LG, Evans RW. Functional status of ESRD patients as measured by the SIP. $f$ Chronic Dis 1987;40 (suppl):117Smeas.

12 McSweeney AJ, Grant I, Heaton RK, Adams KM, Timms RM. Life quality of patients with chronic obstructive RM. Life quality of patients with chronic obstructi
pulmonary disease. Arch Intern Med 1982;142:473-8.

13 Bergner M, Hudson LD, Conrad DA, Patmont CM McDonald GJ, Perrin EB. The cost and efficacy of home care for patients with chronic lung disease. Med Care 1988, 26:566-79.

14 Deyo RA, Diehl AK. Measuring physical and psychosocial function in patients with low back pain. Spine 1983;8:635-42.

15 Follick MJ, Smith TW, Ahern DK. The Sickness Impact Profile: a global measure of disability in chronic low back pain. Pain 1985;21:67-76.
16 Norusis MJ. SPSS Professional Statistics 6.1. Chicago: SPSS

17 Patrick DL, Deyo RA. Generic and disease specific measures in assessing health status and quality of life. Med Care 1989;27:S217-32.

18 Effective Healthcare Bulletin. Management of Cataract. February 1996; Volume 2: Number 3. ISSN:096-0288.

19 Javitt JC, Steinberg EP, Sharkey P, Schein OD, Tielsch JM, Diener West M, et al. Cataract surgery in one eye or both. A billion dollar per year issue. Ophthalmology 1995;105: A billion dollar per year issue. Ophthalmology 1995;105: 1583-93.

0 Steinberg EP, Tielsch JM, Schein OD, Javitt JC, Sharkey P, Cassard SD, et al. National Study of Cataract Surgery Outcomes. Variation in 4-month post-operative outcomes as reflected in multiple outcome measures. Ophthalmology 1994;101:1131-41.

21 Laidlaw A, Harrad R. Can second eye cataract extraction be justified? Eye 1993;7:680-6. 